\title{
MANAJEMEN KONFLIK ANTARBUDAYA PADA ORGANISASI INTERNASIONAL
}

\author{
Ellysabeth Ratih Dwi Hapsari W
}

\begin{abstract}
Communicating effectively with people from different cultures in the workplace is very challenging. Barriers to intercultural communication can occur, such as anxiety, roles and norms, beliefs and values, stereotypes and ethnocentrism. These barriers can cause internal conflict within a group of organizations or companies that have employees with different cultures. Internal conflicts that occur will also prevent the organization to achieve its goals. The current issue is how the management of intercultural communication conflicts occurs in international organizations.

The purpose of this study is to describe the experience of employees of international organizations in the management of intercultural communication conflicts by knowing the negotiation of employee identity, knowing the types and forms of conflict experienced by employees of international organizations and knowing the form of face management in inter-cultural communication conflict management at employees of international organizations. The subject of this research are international organization employees from India, UK, Indonesia and China.

Theory used in this study are Identity Negotiation Theory, Face Negotiation Theory, Effective Intercultural Workgroup in Communication Theory and Thomas and Killman's Conflict Management Model.

The results showed that the negotiation of identity between collectivist and individualist cultures that occurred begins with the interaction between cultures in the form of communication behavior, language, personal character and response from other employees. Differences in ways of thinking and view are the main causes of conflict between individualist and collectivist cultures. Face owned by each culture influences other differences such as how individuals perceive themselves in conflict, self-priority in conflict, and the conflict management style used. Intercultural conflict management that occurs requires a third party as a mediator.
\end{abstract}

\section{Keywords : Intercultural Communication, Conflict Management, International Organization}

\section{PENDAHULUAN}

Konflik antarbudaya dapat terjadi pada organisasi internasional yang memiliki karyawan dari bangsa yang berbeda-beda. Indonesia tergabung pada lebih dari lima puluh organisasi internasional. UN, AFUNPR, UNDP, UNICEF, WHO, WWF dan ERIA adalah sebagian kecil dari organisasi internasional yang berada di Indonesia ${ }^{1}$.
Organisasi internasional ini memekerjakan karyawan yang berasal dari negara yang berbeda. Pada saat ini karyawan yang tergabung dalam organisasi ini berasal dari Cina, Inggris, India, Vietnam, Inggris, Filipina dan Jepang. Peneliti mengetahui fenomena diversity ini dari narasumber peneliti yang merupakan karyawan pada organisasi ini.

Berdasarkan AP, salah satu karyawan

\footnotetext{
${ }^{1}$ Untuk mengetahui organisasi internasional yang digunakan pada penelitian ini, dapat mengirimkan email ke ratihatibie96@gmail.com
} 
terdapat konflik yang ditimbulkan karena perbedaan budaya. Kasus yang terjadi pada organisasi ini contohnya ada pada karyawan yang berasal dari Inggris, saat ia bekerja pertama di organisasi ini ada Indonesia yang memanggilnya "bule". Karyawan yang berasal dari Inggris tersebut marah karena menurutnya hal itu adalah hal yang tidak sopan dan ia mengatakan bahwa karyawan yang berasal dari Indonesia tersebut memiliki mental yang sampah. Karyawan yang berasal dari Indonesia tersinggung dengan pernyataan tersbue karena menurutnya memanggil orangkulit putih dengan sebutan "bule" adalah hal yang wajar, tetapi menurut karyawan Inggris kata itu sangat menyinggung perasaannya. Perbedaan cara berkomunikasi dalam mengungkapkan kata panggilan untuk individu memicuterjadinya konflik antar keduanya. Karyawan Indonesia akhirnya mengaku salah karena dinasehati oleh beberapa kolega-nya dan meminta maaf dan keduanya bisa bekerjasama dengan baik hingga sekarang (data didapatkan melalui wawancara pada tanggal 12 September 2017).

Kasus lainnya adalah perbedaan budaya bekerja antara orang Jepang, yang tidak mengenal waktu, mereka cenderung untuk tidak apa-apa jika bekerja diluar jam kerja yang ada. Bagi karyawan yang berasal dari Jepang, keluarga mereka akan lebih bahagia jika mereka bekerja terus-menerus. Lain hal-nya dengan karyawan lain seperti karyawan yang berasal dari Indonesia karena merasa waktu bersama keluarga terganggu. Hanya saja, karena hal ini merupakan salah satu tanggung jawab pekerjaan, karyawan yang berasal dari Indonesia merasa tidak berhak untuk melakukan protes. Akibat dari perbedaan nilai keluarga pada kasus ini adalah konflik didalam keluarga karena orang Indonesia menekankan pada kebersamaan dalam keluarga dan hari libur bagi karyawan yang berasal dari Indonesia merupakan hari keluarga, sementara karyawan yang berasal dari Jepang tidak mengenal hal ini. Tidak hanya itu saja, terdapat karyawan yang berasal dari Indonesia lain yang akhirnya bercerai karena pihak keluarga tidak bisa menerima jam kerja yang tidak mengenal waktu. Perbedaan nilai yang dimiliki kedua budaya yaitu Jepang dan Indonesia mengakibatkan konflik. Maka dari itu manajer organisasi yang bekerja dalam lingkungan multibudaya perlu memahami apa yang terjadi dalam organisasi, serta mengembangkan kemampuan untuk mengatasi masalah-masalah perbedaan budaya yang timbul (dalam Mulyana dan Rahmat, 2010:56).

Kasus pada organisasi ini misalnya, karyawan yang yang berasal dari Indonesia memanggil karyawan dari Inggris "bule", dan karyawan yang berasal dari Inggris tersinggung. Karyawan yang berasal dari Inggris memiliki karakter budaya individualistik - low-context communication dimana ia akan menyampaikan secara langsung apa yang ia pikirkan. Pada kasus ini ia menyebut karyawan Indonesia dengan sebutan "mental garbage" atau mental sampah. Hal ini dapatmenimbulkanmasalah jika karyawan dalam kebudayaan lain seperti yang berasal dari Indonesia ikut tersinggung, walaupun pada kasus ini ia yangmemulai masalah. Kasus seperti initidak dapat mengakibatkan terjadinya komunikasi antarbudaya yang tidak efektif antar karyawan organisasi ini. Organisasi inipun akan susah untuk menggapai tujuan yang ingin digapai karena karyawan yang berada didalamnya tidak bisa bekerja sama dengan baik.

Dapat disimpulkan bahwa dalam organisasi internasional ini terdapat masalah komunikasi antarbudaya yang berhubungan dengan kurang harmonisnya karyawan dikarenakan proses komunikasi yang terjadi antara individu-individu di ini. Hambatan-hambatan komunikasi antarbudaya tersebut akan berpengaruh semakin burukjika tidak dipahami dengan baik.

\section{RUMUSAN MASALAH}

Peneliti ingin mengetahui bagaimana 
manajemen konflik komunikasi antarbudaya dalam organisasi internasional?

\section{TUJUAN PENELITIAN}

Tujuan penelitian ini adalah untuk mendeskripsikan pengalaman karyawan organisasi internasional dalam pengelolaan konflik komunikasi antarbudaya dengan cara mengetahui negosiasi identitas karyawan, mengetahui jenis dan bentuk konflik yang dialami oleh karyawan organisasi internasional, dan mengetahui bentuk pengelolaan face dalam manajemen konflik komunikasi antarbudaya pada karyawan organisasi internasional

\section{KERANGKA PEMIKIRAN TEORITIS}

Identitas kebudayaan dan etnik sangat penting dan dikaitkan pada beberapa rasa keterkaitan pada kelompok kebudayaan besar seperti kelompok keagamaan, wilayah suatu negara, anggota organisasi tertentu atau bahkan kelompok sesama usia (Ting-Toomey dalam Littlejohn dan Foss, 2009:133).

Beberapa individu dapat mencapai keseimbangan dalam interaksi budaya seperti keadaan bikulturalisme fungsional yaitu ketika anda dapat mempertahankan kebudayaan sendiri tetapi dapat menerima kebudayaan lain secara fleksibel dengan kemampuan lintas budaya. Dan juga keadaan pengubah kebudayaan (cultural transformer) yaitu sebuah keadaan ketika kita mampu berganti dari satu konteks budaya ke budaya lainnya dengan sadar dan mudah (TingToomey dalam Littlejohn dan Foss, 2009:133). Kunci-kunci dari keadaan tersebut adalah kemampuan lintas budaya.

Effective Intercultural Workgroup in Communication Theory yang dijelaskan oleh John Oetzel 1995 (dalam Littlejohn dan Foss, 2009:327) menjelaskan bagaimana keragaman budaya dan keragaman dapat memengaruhi proses komunikasi dan hasil yang terjadi dalam suatu kelompok kerja. Teori ini mencoba mengidentifikasi model kelompok kerja yang efektif yang mengkaji tiga komponen utama yaitu Input-Process-Output Model yang menjelaskan kinerja kelompok dalam sebuah lingkungan multibudaya.

Teori Negosiasi Rupa menjelaskan faktorfaktor berbasis budaya dan situasional yang membentuk tendensi komunikator dalam mendekati dan mengelola konflik. Arti rupa umumnya dikonseptualisasikan seperti bagaimana kita ingin orang lain melihat kita dan memperlakukan kita dan bagaimana kita memperlakukan orang lain bersamaan dengan harapan konsepsi sosial mereka sendiri.

Model manajemen konflik yang dikemukakan oleh Kenneth W. Thomas dan Ralp H. Kilmann (dalam Wirawan 2010:140) ini menjelaskan tentang gaya manajemen konflik. Keduanya mengembangkan taksonomi gaya manajemen konflik berdasarkan dua dimensi : kerja sama pada sumbu horizontal dan keasertifan.

\section{METODE PENELITIAN}

Tipe penelitian yaitu kualitatif dengan pendekatan fenomenologi. Subjek penelitian ini yaitu karyawan organisasi internasional yang memiliki kebudayaan berbeda. Subjek penelitian dipilih karena setiap individu dapat menceritakan lebih mendalam bagaimana proses manajemen konflik dalam organisasi internasional menurut pengalaman masing-masing. Karyawan yang dipilih sebagai subjek penelitian adalah karyawan organisasi internasional yang berasal dari Cina, India, Inggris dan Indonesia. Metode pengumpulan data dengan cara wawancara mendalam (indepth interview).

\section{ANALISIS DAN PEMBAHASAN}

Identitas atau gambaran refleksi-diri, dibentukmelalui negosiasi ketika kita menyatakan, memodifikasi atau menantang identifikasiidentifikasi diri kita atau orang lain(Ting-Toomey 
dalam Littlejohn dan Foss, 2008:132). Identitas informan yang dihasilkan dari interaksi sosial pada studi ini menunjukan bahwa terdapat kesamaan identitas yang terjadi pada informan 1,2,3, dan 4 yaitu mereka merasa nyaman dan percaya kepada karyawan lain dalam hal pekerjaan, selain itu mereka juga merasa nyaman dengan identitas budaya yang dimiliki masing-masin. Kesamaan lainnya yang dialami oleh keempat informan adalah mereka tidak merasa ada respon negatif yang diberikan oleh karyawan lain terhadap identitas budayanya, walaupun bagi informan 4 ia tidak bisa memastikan karena beberapa karyawan pada organisasi ini yang ia kenal adalah orang yang sopan seperti karyawan yang berasal dari Indonesia.

Pengalaman unik yang ditemukan pada studi ini adalah terdapat perbedaan cara dalam berkomunikasi yang dimiliki masing-masing informan. Informan 1 memiliki aksen yang terkadang menjadi bahan bercanda karyawan lain, informan 2 lebih menyukai komunikasi yang tidak langsung, sementara informan 3 lebih suka komunikasi yang langsung dan informan 4 berbicara cepat sambil menggerakan kepalanya ke kiri dan ke kanan, dalam berbicara ia juga menggunakan tata krama agar tidak menyakiti hati karyawan lain. Persamaan yang dimiliki keempat informan adalah mereka berkomunikasi dengan menggunakan Bahasa Inggris.

Dalam Teori Negosiasi Identitas (TingToomey dalam Littlejohn dan Foss, 2008:133) dikatakan bahwa beberapa individu dapat mencapai keseimbangan dalam interaksi budaya seperti keadaan bikulturalisme fungsional yaitu ketika informan dapat mempertahankan kebudayaan sendiri tetapi dapat menerima kebudayaan lain juga dan pengubah kebudayaan (cultural transformer) yaitu sebuah keadaan ketika informan mampu berganti dari satu konteks budaya ke budaya lainnya dengan sadar dan mudah. Temuan penelitian ini menunjukan bahwa informan 1 dan 2 mengalami keseimbangan budaya dengan keadaan bikulturalisme fungsional karena informan 1 tetap menggunakan aksen british dalam berkomunikasi, sementara informan 2 tetap mempertahankan identitasnya sebagai bangsa Indonesia yang menganut kebudayaan Australia, tetapi tidak mempermasalahkan budaya satu sama lain. Hal ini dapat dilihat dari para informan yang merasa nyaman dengan karyawan lain, walaupun bangsanya berbeda.

Pada informan 3 dan 4, mereka mengalami keseimbangan budaya dalam keadaan cultural transformer karena ia menyesuaikan dirinya saat bertemu orang lain. Informan 4 mengaku jika ia berada di ruangannya ia akan menjadi karyawan yang berasal dari India yang profesional, sementara jika ia berada di rumah ia akan menjadi orang India seutuhnya. Informan 3 membedakan cara berkomunikasinya sesuai dengan budaya dari karyawan, jika ia berbicara dengan karyawan dari Indonesia maka ia akan lambat. Ia juga melihat karyawan lain yang berbeda bangsa sebagai individu.

Kepuasan hasil dari negosiasi identitas dalam Teori Negosiasi Identitas meliputi rasa dimengerti, dihargai, dan didukung. Dalam penelitian ini ditemukan dampak dari kepuasan hasil dari negosiasi identitas yaitu, negosiasi identitas yang terjadi pada informan 3 menghasilkan hubungan pribadi antara dirinya dan karyawan yang berasal dari Inggris. Hal ini membuat mereka sering bertamasya bersama. Berbeda dengan informan 1, 2, dan 4 merasa hubungan yang ada pada organisasi ini hanya sebatas teman kerja dan hubungan profesional. Dalam penelitian ini ditunjukan bahwa kepuasan negosiasi identitas tidak hanya sebatas rasa yang dirasakan oleh informan, tetapi juga hubungan yang dapat terjadi diluar pekerjaan.

Cole (dalam Martin dan Nakayama, 2010:437) menjelaskan bahwa terdapat beberapa jenis konflik. Berdasarkan temuan penelitian terdapat kesamaan jenis konflik pada keempat informan. Jenis konflik yang mereka 
miliki adalah jenis konflik kognitif. Situasi yang terjadi pada jenis konflik kognitif adalah dimana dua atau lebih orang sadar bahwa proses berpikir atau persepsi mereka tidak sesuai. Kesamaan lainnya adalah bentuk konflik yang dialami informan 1,2,3, dan 4 yaitu, konflik yang diawali dari perbedaan pendapat.

Keempat informan mengalami perbedaan dalam penyebab konflik dari masing-masing informan. Informan 1 mengalami konflik yang disebabkan oleh perbedaan budaya kerja yang dimilikinya dengan karyawan yang berasal dari dari Jepang, informan 2 mengalami konflik yang disebabkan oleh karyawan yang berasal dari Filipina yang terlalu keras dan mencampurkan emosi dalam rapat, sementara dirinya tidak suka mencampuri emosi dalam hal pekerjaan dan informan 3 dan 4 yang mengalami persamaan penyebab konflik yaitu, perbedaan cara menyelesaikan konflik yang dimiliki masingmasing individu, dimana informan 3 lebih menyukai penyelesaian konflik secara langsung dan informan 4 merasa tidak cocok dengan karyawan yang berasal dari Cina yang dianggapnya terlalu agresif dalam menanggapi konflik.

Dalam studi ini ditemukan bahwa, terdapat perbedaan dalam cara melihat diri dalam konflik pada masing-masing informan. Perbedaan yang terjadi adalah informan 1 menghindari konflik, informan 2 tidak melibatkan emosi dalam komunikasi yang ia lakukan dengan karyawan lain dari berbeda bangsa, informan 3 lebih menyukai konflik yang diselesaikan secara langsung tanpa perantara dan informan 4 merupakan pribadi yang pemaaf dan tidak pendendam.

Pada Face Negotiation Theory dijelaskan bahwa kolektivisme-individualisme dan jarak kekuasaan (power distance) memengaruhi rupa informan. Berdasarkan penelitian ini ditemukan bahwa Informan 1 dan 3 memiliki persamaan, mereka memiliki face yang individualis karena menyelesaikan konflik sesuai dengan apa yang menurut mereka benar sebagai individu, tidak melihat kepentingan kelompok. Berbeda dengan informan 2 dan 4 yang memilikiface kolektivisme karena informan 2 menyelesaikan konflik dengan menyesuaikan regulasi yang ada pada organisasi dan informan 4 akan melihat keputusan yang terbaik untuk organisasi ini. Jarak kekuasaan (power distance) yang ada pada face keempat informan terdapat kesamaan yaitu pada lowpower distance dimana komunikasi lebih langsung dan bersifat pribadi karena tidak ada yang menggunakan kekuasaan dan jabatannya dalam pengambilan keputusan yang terjadi pada konflik masing-masing informan.Berdasarkan penelitian ini, ditemukan juga bahwa selain kolektivis-individualisme dan jarak kekuasaan (power distance) cara informan melihat jabatan kolega juga dapat memengaruhi cara mereka untuk menyelesaikan konflik. Dalam penelitian ini informan 1, 3, dan 4 tidak melihat jabatan dari koleganya saat menghadapi konflik, namun berbeda dengan informan 2, ia akan melihat jabatan dari koleganya, ketika jabatannya lebih tinggi maka ia akan berusaha berkomunikasi dengan cara yang lebih sopan, sehingga pada penelitian ini jabatan dapat memengaruhi informan dalam menyelesaikan konflik.

Dalam Effective Intercultural Workgroup Communication Theory, terdapat Input-Process-Output Model yang menjelaskan kinerja kelompok dalam sebuah lingkungan multibudaya. Keragaman budaya dapat memengaruhi proses komunikasi dan hasil yang terjadi dalam suatu kelompok kerja (Oetzel, 2011:147). Pengaruh atas fungsi kelompok diawali dengan masukan tertentu berupa informasi, seseorang atau perubahan lingkungan. Konflik yang dialami masing-masing informan adalah sebuah masukan yang memengaruhi komunikasi dan hasil dari organisasi ini. Teori ini membagi masyarakat dalam tiga karakter yaitu individualistik-kolektivistik, pemahaman selfconstrual dan face concerns masing-masing 
(Oetzel, 2011:147). Karakter yang dimiliki informanmemengaruhi proses komunikasi melalui beberapa cara. Telah dijelaskan sebelumnya bahwa informan 1 dan 3 memiliki kebudayaan individualis dimanamereka mementingkan pribadi di atas tujuan kelompok. Dalam konflik yang dialami oleh informan 1 dan 3 mereka juga mementingkan self-face atau diri sendiri. Mereka juga menggunakan komunikasi secara langsung, sementara informan 2 dan 4 yang memiliki kebudayaan kolektivis mementingkan mutualface dimana keputusan yang mereka lakukan menyesuaikan dengan kebutuhan organisasi dan tujuan kelompok.

Self Construal adalah cara seseorang berfikir tentang diri sendiri. Pada informan 2 dan 4 mereka menghindari hal yang dapat menyakiti hati karyawan lain. Berbeda dengan informan 1 dan 3 yang memiliki karakter budaya individualistis, informan 1 tetap merasa dirinya sama dengan karyawan lain dan tidak memandang dirinya unik dan informan 3 merasa harus memahami setiap karyawan sebagai individu dan menyesuaikan komunikasinya sesuai budaya yang mereka miliki. SelfConstrual yang dimiliki informan 1, 2,3, dan 4 adalah interpenden yaitu lebih fokus dengan bagaimana mereka terhubung dengan karyawan lain, walaupun informan 1 dan 3 adalah individualis dan informan 2 dan 4 adalah kolektivis, mereka tetap memiliki self construal yang sama.

Gaya manajemen konflik milik Thomas dan Killman (dalam Wirawan 2010:140) mengemukakan lima jenis gaya yaitu kompetisi, kolaborasi, kompromi, menghindar dan mengakomodasi. Pada penelitian ini ditemukan bahwa gaya manajemen konflik yang dimiliki para informan memiliki perbedaan. Gaya manajemen yang dimiliki oleh informan 1, 3, dan 4 adalah kompromi, dimana kedua belah pihak yang terlibat konflik mencari alternatif yang dapat memuaskan kedua pihak. Berbeda dengan informan 2 yang menyelesaikan konflik dengan cara menghindar terlebih dahulu dan keesokan harinya mendiskusikan lagi konfliknya dengan karyawan dari Filipina. Dengan gaya manajemen konflik yang berbeda, para informan tetap dapat menyelesaikan konflik yang ada.

Komunikasi yang dilakukan para informan termasuk komunikasi yang efektif karena terdapat partisipasi yang setara pada informan 1,2,3, dan 4 dalam konflik yang dialami dengan karyawan lain. Pengambilan keputusan konsensus pada konflik yang dialami, konflik tidak melihat kekuasaan satu pihak saja, walaupun pada informan 1 konflik yang dirasakan adalah dengan atasan, tetapi tetap ada konsensus yang terjadi sehingga solusi yang dapat menyenangkan kedua pihak dapat tercapai. Konflik yang dirasakan oleh informan juga kooperatif, para informan mau menyelesaikan konflik walaupun dengan cara masing-masing dan komunikasi yang saling menghormati, walaupun pada informan 4 awalnya ia tidak merasa dihormati oleh karyawan yang berasal dari Cina, pada akhirnya karyawan tersebut mau meminta maaf dan mengakui kesalahannya.

Teori ini juga memiliki konsep yang menjelaskan bahwa jika sebuah kelompok memiliki komunikasi yang efektif, hal ini juga akan meningkatkan kualitas hubungan antarbudaya yang dimiliki karyawan diluar kelompok kerja tersebut (Oetzel dalam Littlejohn dan Foss, 2009:328). Dalam studi ini ditemukan bahwa komunikasi efektif yang terjadi tetap dapat menimbulkan komunikasi tidak akrab yang dimiliki informan, karena hubungan yang terjadi pada informan hanya sebatas pekerjaan. Berdasarkan penelitian ini hanya informan 3 saja yang memiliki hubungan pribadi dengan karyawan lain, sementara informan 4 mengatakan walaupun konflik dapat terselesaikan dengan bantuan dari atasan, komunikasi yang ia lakukan dengan karyawan Cina yang memiliki konflik dengannya tetap sebatas teman kerja saja. 


\section{PENUTUP}

\section{Kesimpulan}

Berdasarkan hasil penelitian dan pembahasan yang telah disajikan, maka dapat disimpulkan sebagai berikut:

a. Negosiasi identitas antara budaya kolektivistik dan individualistik yang terjadi diawali dengan interaksi antarabudaya berupa perilaku komunikasi, bahasa yang digunakan, karakter personal individu dan respon dari karyawan lain. Hal tersebut menghasilkan keseimbangan interaksi budaya dan kepuasan yang meliputi rasa dimengerti, dihargai, didukung dan hubungan pribadi antara individu diluar pekerjaan. Kendala dalam negosiasi identitas berupa adaptasi budaya yang dialami oleh informan karena gaya manajemen yang mengikuti budaya Jepang.

b. Perbedaan cara berpikir dan pandangan menjadi penyebab utama konflik antara budaya individualistis dan kolektivis. Konflik yang terjadi memiliki kesamaan jenis yaitu kognitif, dimana terdapat dua atau lebih orang yang memiliki persepsi berbeda.

c. Face yang dimiliki budaya individualistik dan kolektivistik memengaruhi perbedaan lainnya seperti cara individu melihat diri mereka dalam konflik, prioritas diri dalam konflik, dan gaya manajemen konflik yang digunakan individu. Gaya manajemen konflik yang digunakan adalah kompromi dan menghindar.

d. Manajemen konflik yang terjadi antara budaya individualistik dan kolektivistik membutuhkan pihak ketiga sebagai penengah atau mediator untuk membantumenyelesaikan konflik yang dialami oleh para informan.

e. Manajemen konflik antara budaya individualistik dan kolektivistik diawali dengan konflik sebagai masukan. Proses penyelesaian dipengaruhi oleh face yang dimiliki masing-masing budaya dan gaya manajemen konflik yang digunakan. Keluaran dalam manajemen konflik ini berupa kualitas hubungan antara karyawan budaya individulistik dan kolektivistik (hubungan akrab dan tidak akrab).

\section{Implikasi}

a. Implikasi Teoritik

Penggunaan Teori Negosiasi Identitas dalam penelitian ini belum bisa menjangkau proses adaptasi budaya yang dapat dirasakan oleh karyawan dari bangsa berbeda, selain itu teori ini juga tidak bisa menjangkau karakter individu sebagai hal yang memengaruhi proses negosiasi identitas. Penelitian ini memberikan konsep tambahan yaitu kendala dalam beradaptasi dapat terjadi dalam proses negosiasi identitas dan selain budaya yang dimiliki masing-masing individu, karakter individu juga dapat memengaruhi hasil negosiasi identitas yang terjadi pada suatu lingkungan kerja multibudaya.

Gaya manajemen konflik milik Thomas dan Killman (dalam Wirawan 2010:140) mengemukakan lima jenis gaya yaitu kompetisi, kolaborasi, kompromi, menghindar dan mengakomodasi. Penelitian ini memberikan konsep tambahan berupa kebutuhan para informan akan pihak ketiga dalam proses penyelesaian konflik yang terjadi.

b. Implikasi Praktis

Penelitian ini memberikan penjelasan tentang manejemen konflik antarbudaya pada organisasi internasional. Pengalaman individu-individu dalam penelitian ini dapat menjadi referensi dan juga panduan bagi manajerial organisasi internasional yang mengalami konflik ketika berinteraksi dengan karyawan dari bangsa berbeda.

c. Implikasi Sosial

Melalui penelitian ini, khususnya bagi masyarakat dan kelompok dari bangsa berbeda dapat lebih saling mengerti karakter 
dari masing-masing budaya, sekaligus berguna untuk mencegah konflik sosial yang dapat terjadi di kemudian hari.

\section{Rekomendasi}

a. Penelitian selanjutnya dapat menggunakan pendekatan mix (kuantitatif dan kualitatif) untuk menjawab kendala yang lebih rumit dalam melakukan negosiasi identitas dan manajemen konflik pada lingkungan kerja yang memiliki karyawan yang berasal dari bangsa berbeda.

b. Penelitian selanjutnya juga dapat memperluas subjek penelitian seperti perusahaan multinasional dengan profit untukmemberikan indikasi lain yang dapat terjadi dalam negosiasi identitas dan manajemen konflik dalam lingkungan kerja berbeda bangsa.

c. Penelitian selanjutnya dapat mempergunakan perspektif yang berbeda dengan menggunakan paradigma kritikal yang mencoba melihat pengalaman individu terkait dengan kelompok dominan yang ada pada lingkungan kerja dengan bangsa berbeda. Pada aspek inilah kemungkinan akan diketahui komunikasimanajemen konflik yang terjadi, jika terdapat budaya yang dominan pada kelompok.

\section{DAFTAR PUSTAKA}

Littlejohn \& Foss. (2009). Theories of Human Communication. California: Sage Publications

LittleJohn \& Foss. (2009). Encyclopedia of communication theory. California: Sage Publications Liliweri, Alo (2004). Dasar-dasar Komunikasi Antarbudaya. Yogyakarta : Pustaka Pelajar

Moleong, Lexy J. (2007). Metodologi Penelitian Kualitatif-Edisi Revisi. Bandung: PT. Remaja Rosdakarya (2009).

Moustakas, Clark. (1994). Phenomenological Research Methods. California: Sage Publications.

Mulyana, Deddy dan Jalaluddin Rakhmat. (2010). Komunikasi Antarbudaya). Bandung : Remaja Rosdakarya.

Mulyana, Deddy. (2005). Komunikasi Efektif. Suatu Pendekatan Lintasbudaya (2nd Edition ed.). Bandung: Remaja Rosdakarya.

Mulyana, Deddy. (2003). Metode Penelitian Kualitatif. Bandung: Remaja Rosdakarya.

Nakayama, Thomas K. Dan Judith Martin.(2010). Intercultural Communication in Contexts. United States : The McGraw-Hill Companies, Inc.

Neuman,W. Lawrence. (2003). Social Research Methods. Qualitative and Quantitative Approaches. Boston :Ally and Bacon

Pace, R.Wayne dan Don F. Faules. (2004). Komunikasi Organisasi. Bandung : Remaja Rosdakarya Salim, Agus. (2006). Teori \& Paradigma Penelitian Sosial. Yogyakarta: Tiara Wacana. 
Samovar, Larry dkk. (2010). Intercultural Communication :Areader 13th Edition. Boston : Wadsworth Cengage Learning.

Wirawan. (2010). Konflik dan Manajemen Konflik: Teori dan Aplikasi. Jakarta: Salemba Humanika

Nnia, Ike pada Juni 2015. Conflicts Encourntered by Multinational Corporations in Cross-Cultural Communication and its Solutions. Journal of International Business and Economics Vol.3, No.1, pp. 86-92.

Prause, Daria pada tahun 2015. Conflict Management Practices for Diverse Workplaces. Journal of Business Studies Quarterly 2015, Volume 6, No.3.

Rozkwitalska, $\mathrm{Ma}^{3}$ gorzata pada tahun 2013. Effective Cross-cultural Relationships in Multinational Business Strategy and Organizational Behaviour (BizStraetgy 2013), ISNN: 2251-1970.

Sari, Maduma Yanti pada tahun 2017. Komunikasi Antarbudaya Studi Negosiasi Wajah Dalam Interaksi Etnik Batak dan Etnik Minang di Duri Kelurahan Gajah Sakti Kecamatan Mandau Kabupaten Bengkalis. JOM FISIP Vol. 4 No. 2.

Terdjakusuma, Ferdika dan Eddy Madiono Sutanto. (2015.) Komunikasi Antar Karyawan Etnis Jawa dan Tionghoa. Surabaya : JMK. Vol. 17, No.2n

Ting-Yoomey pada tahun 2015. Identity Negotiation Theory. In J. Bennett (Ed.), Sage Encyclopedia of Intercultural Competence, Volume 1(pp. 418-422). Los Angeles, CA:Sage.

Oetzel, John dkk pada tahun 2011. The Impact of Individual Differences and Group Diversity on Group Interaction Climate and Satisfaction: A Test of the Effective Intercultural Workgroup Communication Theory, Vol. 5, No. 2, pp. 144-167.

https://www.kemlu.go.id/Documents/Keanggotaan_Indonesia_pada_OI.pdf 